\title{
Preoperative embolization versus no embolization for WHO grade I intracranial meningioma: a retrospective matched cohort study
}

\author{
Colin J. Przybylowski, MD, Xiaochun Zhao, MD, Jacob F. Baranoski, MD, \\ Leandro Borba Moreira, MD, Sirin Gandhi, MD, Kristina M. Chapple, PhD, Kaith K. Almefty, MD, \\ Nader Sanai, MD, Andrew F. Ducruet, MD, Felipe C. Albuquerque, MD, Andrew S. Little, MD, and \\ Peter Nakaji, MD
}

Department of Neurosurgery, Barrow Neurological Institute, St. Joseph's Hospital and Medical Center, Phoenix, Arizona

\begin{abstract}
OBJECTIVE The controversy continues over the clinical utility of preoperative embolization for reducing tumor vascularity of intracranial meningiomas prior to resection. Previous studies comparing embolization and nonembolization patients have not controlled for detailed tumor parameters before assessing outcomes.
\end{abstract}

METHODS The authors reviewed the cases of all patients who underwent resection of a WHO grade I intracranial meningioma at their institution from 2008 to 2016. Propensity score matching was used to generate embolization and nonembolization cohorts of 52 patients each, and a retrospective review of clinical and radiological outcomes was performed.

RESULTS In total, 52 consecutive patients who underwent embolization (mean follow-up $34.8 \pm 31.5$ months) were compared to 52 patients who did not undergo embolization (mean follow-up $32.8 \pm 28.7$ months; $p=0.63$ ). Variables controlled for included patient age $(p=0.82)$, tumor laterality $(p>0.99)$, tumor location $(p>0.99)$, tumor diameter $(p=$ 0.07 ), tumor invasion into a major dural sinus ( $p>0.99$ ), and tumor encasement around the internal carotid artery or middle cerebral artery $(p>0.99)$. The embolization and nonembolization cohorts did not differ in terms of estimated blood loss during surgery ( $660.4 \pm 637.1 \mathrm{ml}$ vs $509.2 \pm 422.0 \mathrm{ml} ; p=0.17$ ), Simpson grade IV resection $(32.7 \%$ vs $25.0 \% ; p$ $=0.39$ ), perioperative procedural complications $(26.9 \%$ vs $19.2 \%$; $p=0.35)$, development of permanent new neurological deficits ( $5.8 \%$ vs $7.7 \% ; p=0.70$ ), or favorable modified Rankin Scale (mRS) score (a score of $0-2$ ) at last follow-up $(96.0 \%$ vs $92.3 \% ; p=0.43)$, respectively. When comparing the final mRS score to the preoperative mRS score, patients in the embolization group were more likely than patients in the nonembolization group to have an improvement in $\mathrm{mRS}$ score $(50.0 \%$ vs $28.8 \% ; p=0.03)$.

CONCLUSIONS After controlling for patient age, tumor size, tumor laterality, tumor location, tumor invasion into a major dural sinus, and tumor encasement of the internal carotid artery or middle cerebral artery, preoperative meningioma embolization intended to decrease tumor vascularity did not improve the surgical outcomes of patients with WHO grade I intracranial meningiomas, but it did lead to a greater chance of clinical improvement compared to patients not treated with embolization.

https://thejns.org/doi/abs/10.3171/2020.1.JNS19788

KEYWORDS embolization; meningioma; Onyx; tumor; oncology

$\mathrm{T}$ HE clinical utility of preoperative embolization to reduce the vascularity of intracranial meningiomas remains highly debated. ${ }^{20}$ The goal of preoperative tumor devascularization is to induce tumor necrosis, which is theoretically expected to decrease operative blood loss, increase tumor softness, and decrease operative duration. While some studies have suggested that these benefits exist after preoperative embolization, ${ }^{2,7,8}$ others have not. ${ }^{17}$ Furthermore, others have reported unacceptably high complication rates. ${ }^{18,19}$ Given the added morbidity associ-

ABBREVIATIONS EBL = estimated blood loss; ICA = internal cerebral artery; ICP = intracranial pressure; MCA = middle cerebral artery; mRS = modified Rankin Scale; $\mathrm{nBCA}=\mathrm{N}$-butyl cyanoacrylate; NIS $=$ National (Nationwide) Inpatient Sample.

SUBMITTED March 19, 2019. ACCEPTED January 13, 2020.

INCLUDE WHEN CITING Published online March 27, 2020; DOI: 10.3171/2020.1.JNS19788. 
ated with an additional surgical procedure, most neurosurgeons await clear evidence that preoperative embolization improves surgical and patient outcomes before adopting it into their standard clinical practice.

As embolysate technology has evolved over the last decade, several studies have been published on the safety and efficacy of preoperative meningioma embolization, , , 13,16,17, 24,25 but none have adequately matched their patients to a nonembolization control group by controlling for detailed tumor-related parameters, which limits the interpretation of previously published findings. In this study, we controlled for important patient- and tumor-related variables between embolization and nonembolization cohorts to assess the effect of preoperative embolization on the surgical outcomes of patients with intracranial meningiomas.

\section{Methods \\ Patient Selection}

This is a retrospective matched cohort study of patients with WHO grade I intracranial meningiomas treated with resection, with or without preoperative embolization, at the Barrow Neurological Institute between January 1, 2008, and December 31, 2016. Data from all eligible patients who underwent resection of a WHO grade I intracranial meningioma at our institution during the study period were included for analysis. The exclusion criteria included atypical or anaplastic histopathology, age $<18$ years, a diagnosis of meningiomatosis, or follow-up duration $<6$ months. There were a total of 52 embolization patients over this study period, and these patients were used as a consecutive series in the treatment arm of the study. This study was approved by the St. Joseph's Hospital and Medical Center Institutional Review Board for Human Research in Phoenix, Arizona. Informed patient consent for the analysis was not required because of the retrospective nature of the study; all patients or their guardians consented to undergoing the neurosurgical procedures described in the study.

Preoperative meningioma embolization was employed at the request of the operating neurosurgeon throughout the study period. Thus, strict selection criteria for the use of preoperative embolization were not implemented. Typically, embolization was requested in cases involving large tumors with prominent vascular flow voids observed on preoperative MRI, but, ultimately, the decision was based on surgeon preference.

\section{Cohort Matching}

To generate matching cohorts of embolization and nonembolization patients, the following patient-, tumor-, and treatment-related variables were first collected via review of medical records and operative reports: age, preoperative embolization status, tumor laterality, tumor diameter (determined as the maximum diameter in the axial, coronal, or sagittal plane), tumor location, presence of tumor invasion into a major dural sinus (sinus invasion), and presence of tumor encasement around the internal cerebral artery (ICA) or middle cerebral artery (MCA) (ICA/MCA encasement). Patients were then divided into embolization and nonembolization cohorts on the basis of whether they did or did not undergo preoperative embolization, respectively.

To minimize confounding patient- and tumor-related variables between the embolization and nonembolization groups, greedy data matching was performed with NCSS version 1.0 (NCSS LLC). The goal of greedy data matching was to produce balanced groups on the basis of a set of covariates or a propensity score. A 1:1 matching ratio between the two groups was used because the quality of the match deteriorated when this ratio was increased to 2:1. One-to-one forced-match variables included tumor laterality, tumor location, sinus invasion, and ICA/MCA encasement. For the continuous variables of age and tumor diameter, the success of the match was determined on the basis of the change in $p$ value and the standardized difference after matching. We aimed for a standardized difference of $<10 \%$ after matching.

\section{Clinical and Radiological Assessment}

Complete detailed patient, tumor, operative, and outcome data were then collected by direct chart and neuroimaging review after successful cohort matching. For patients who underwent preoperative embolization, detailed neurological examinations were documented after embolization and before tumor resection to identify new medical or surgical complications related to the endovascular procedure. Patients were typically followed up in the outpatient clinic by the attending neurosurgeon at 4 weeks, 3 months, 6 months, and 1 year postoperatively, unless the patient had a persistent neurological deficit, in which case the patient was seen yearly thereafter. New neurological deficits were considered chronic if the patient had not made a complete recovery to his/her preoperative neurological status by last follow-up. In addition to focal neurological deficits, clinical outcomes were measured with the modified Rankin Scale (mRS). An mRS score of $>2$ was considered poor functional status. mRS score improvement was defined as an improvement by at least 1 grade in the final $\mathrm{mRS}$ score compared to the preoperative mRS status for each patient.

All brain MR images and cerebral angiograms were independently reviewed. Tumor location was defined by the following anatomical locations: convexity, falcine, tentorial, anterior skull base, middle skull base, and posterior skull base. The major dural sinuses evaluated for tumor invasion included the sagittal sinus, torcula, transverse sinus, and sigmoid sinus. MRI scans were obtained postoperatively at $<48$ hours, 6 months, 2 years, and every 5 years thereafter. In patients for whom evaluable data were available, the volumetric extent of tumor resection was calculated with manual segmentation with region-of-interest analysis on contrast-enhanced T1-weighted MR images. ${ }^{21}$ The percentage of tumor devascularization after embolization was estimated on the basis of the pre-embolization and postembolization angiographic blush.

\section{Statistical Methods}

Continuous variables are presented as mean (range) or $\pm \mathrm{SD}$, and categorical variables are presented as the frequency (percentage). Independent-sample t-tests and chisquare tests were used to compare groups. SPSS version 
TABLE 1. Comparison of $p$ values before and after statistical matching for select variables

\begin{tabular}{lcc}
\hline \multicolumn{1}{c}{ Variable } & $\begin{array}{c}p \text { Value Before } \\
\text { Matching }\end{array}$ & $\begin{array}{c}p \text { Value After } \\
\text { Matching }\end{array}$ \\
\hline Age & 0.18 & 0.82 \\
\hline Tumor laterality & 0.15 & $>0.99$ \\
\hline Tumor diameter & $<0.001$ & 0.07 \\
\hline Tumor location & $<0.001$ & $>0.99$ \\
\hline Sinus invasion & 0.05 & $>0.99$ \\
\hline ICA/MCA encasement & 0.48 & $>0.99$ \\
\hline
\end{tabular}

24 (IBM Corp.) was used for all analyses. Any p values < 0.05 were considered statistically significant. Propensity score matching methods were discussed above.

\section{Results}

Between January 1, 2008, and December 31, 2016, 1441 patients at the Barrow Neurological Institute underwent resection of a WHO grade I intracranial meningioma. A total of 688 patients were excluded on the basis of our selection criteria, yielding 753 patients for inclusion in the study. Of these 753 patients, 52 (7\%) underwent preoperative embolization and $701(93 \%)$ did not.

\section{Cohort Matching}

From the group of 701 nonembolization patients, a control cohort $(n=52)$ was generated to match the treatment cohort of embolization patients $(n=52)$ using the aforementioned methodology. Between the embolization and nonembolization groups, the forced-match variables of tumor laterality, tumor location, sinus invasion, and ICA/ MCA encasement were perfectly matched ( $p>0.99$ for all; Table 1). For the continuous variable age, the standardized difference improved from $-1967 \%$ to $4.5 \%(\mathrm{p}=0.82)$ after matching. For the continuous variable tumor diameter, the standardized difference improved from $139.7 \%$ to $36.1 \%(p=0.07)$ after matching. The mean maximum tumor diameters before matching were $5.0 \pm 1.4 \mathrm{~cm}$ versus $3.1 \pm 1.4 \mathrm{~cm}$ in the embolization and nonembolization groups, and these improved to $5.0 \pm 1.4 \mathrm{~cm}$ versus $4.5 \pm$ $1.4 \mathrm{~cm}$ after matching. While we were unable to match patients on this variable with a standardized difference < $10 \%$, the absolute difference between the mean maximum tumor diameters was small after matching, so we believe that a reliable and practical comparison between the two groups of 52 patients each was justified.

\section{Patient and Tumor Characteristics}

Patient- and tumor-related variables are shown in Table 2. The mean age was $55.8 \pm 13.1$ years in the embolization group and $55.3 \pm 11.9$ years in the nonembolization group $(\mathrm{p}=0.82)$. In the embolization group, 38 patients $(73.1 \%)$ were female compared to $39(75.0 \%)$ in the nonembolization group $(\mathrm{p}=0.82)$. The tumors in both groups were located on the left side in 22 cases (42.3\%), right side in 27 cases $(51.9 \%)$, and midline in 3 cases $(5.8 \%)$. The tumors were most commonly located along the convexity (each group: $\mathrm{n}=17$ [32.7\%]), followed by the tentorium (each

TABLE 2. Patient and tumor characteristics

\begin{tabular}{|c|c|c|c|c|}
\hline Variable & $\begin{array}{l}\text { Overall Population } \\
\quad(n=104)\end{array}$ & $\begin{array}{c}\text { Embolization } \\
\text { Cohort }(n=52)\end{array}$ & $\begin{array}{l}\text { Nonembolization } \\
\text { Cohort }(n=52)\end{array}$ & $p$ Value \\
\hline Age, yrs & $55.5 \pm 12.5$ & $55.8 \pm 13.1$ & $55.3 \pm 11.9$ & 0.82 \\
\hline Sex, female & $77(74.0 \%)$ & $38(73.1 \%)$ & $39(75.0 \%)$ & 0.82 \\
\hline Max diameter, $\mathrm{cm}$ & $4.7 \pm 1.4$ & $5.0 \pm 1.4$ & $4.5 \pm 1.4$ & 0.07 \\
\hline Sinus invasion & $10(9.6 \%)$ & $5(9.6 \%)$ & $5(9.6 \%)$ & $>0.99$ \\
\hline ICA/MCA encasement & $6(5.8 \%)$ & $3(5.8 \%)$ & $3(5.8 \%)$ & $>0.99$ \\
\hline Laterality & & & & $>0.99$ \\
\hline Left & $44(42.3 \%)$ & $22(42.3 \%)$ & $22(42.3 \%)$ & \\
\hline Right & $54(51.9 \%)$ & $27(51.9 \%)$ & $27(51.9 \%)$ & \\
\hline Midline & $6(5.8 \%)$ & $3(5.8 \%)$ & $3(5.8 \%)$ & \\
\hline Location & & & & $>0.99$ \\
\hline Convexity & $34(32.7 \%)$ & $17(32.7 \%)$ & $17(32.7 \%)$ & \\
\hline Falcine & $10(9.6 \%)$ & $5(9.6 \%)$ & $5(9.6 \%)$ & \\
\hline Skull base anterior & $10(9.6 \%)$ & $5(9.6 \%)$ & $5(9.6 \%)$ & \\
\hline Skull base middle & $20(19.2 \%)$ & $10(19.2 \%)$ & $10(19.2 \%)$ & \\
\hline Skull base posterior & $6(5.8 \%)$ & $3(5.8 \%)$ & $3(5.8 \%)$ & \\
\hline Tentorial & $24(23.1 \%)$ & $12(23.1 \%)$ & $12(23.1 \%)$ & \\
\hline Preop mRS score & & & & 0.24 \\
\hline $0-2$ & $99(95.2 \%)$ & $51(98.1 \%)$ & $48(92.3 \%)$ & \\
\hline $3-5$ & $5(4.8 \%)$ & $1(1.9 \%)$ & $4(7.7 \%)$ & \\
\hline
\end{tabular}

Values are presented as the number $(\%)$ of patients or as the mean \pm SD unless otherwise indicated. 
TABLE 3. Surgical outcomes

\begin{tabular}{lcccc}
\hline \multicolumn{1}{c}{ Outcome } & $\begin{array}{c}\text { Embolization Cohort } \\
(\mathrm{n}=52)\end{array}$ & $\begin{array}{c}\text { Nonembolization Cohort } \\
(\mathrm{n}=52)\end{array}$ & $p$ Value & $\begin{array}{c}\text { Odds Ratio } \\
(95 \% \mathrm{Cl})\end{array}$ \\
\hline EBL, $\mathrm{ml}$ & $660.4 \pm 637.1$ & $509.2 \pm 422.0$ & 0.17 & \\
\hline Simpson resection grade & & & & \\
\hline I & $15(28.9 \%)$ & $11(21.2 \%)$ & & \\
\hline II & $19(36.5 \%)$ & $22(42.3 \%)$ & & \\
\hline III & $1(1.9 \%)$ & $6(11.5 \%)$ & & \\
\hline IV & $17(32.7 \%)$ & $13(25.0 \%)$ & 0.39 & $1.46(0.62-3.42)$ \\
\hline
\end{tabular}

Values are presented as the number (\%) of patients or as the mean \pm SD unless otherwise indicated.

group: $\mathrm{n}=12$ [23.1\%]). Preoperatively, 1 patient $(1.9 \%)$ in the embolization group and 4 patients $(7.7 \%)$ in the nonembolization group had poor functional status (mRS score $>2 ; \mathrm{p}=0.24)$.

\section{Endovascular Embolization}

Embolization was performed successfully in all 52 patients in the embolization group. The tumors in this group were fed by a mean of 2 arterial pedicles (range 1-5 pedicles). One pedicle was successfully embolized in 40 cases, while 2 pedicles were successfully embolized in 12 cases. The embolysates used were ethylene vinyl alcohol (Onyx; Medtronic) alone in 39 cases (75\%), Onyx plus N-butyl cyanoacrylate (nBCA) in 5 cases $(9.6 \%)$, nBCA alone in 4 cases $(7.7 \%)$, Onyx plus particles in 2 cases $(3.8 \%)$, and particles alone in 2 cases $(3.8 \%)$. The mean percentage of tumor devascularization was estimated to be $58 \%$ (range $5 \%-100 \%$ ). Resection was performed at a mean of 2.9 days after embolization (range 0-33 days).

\section{Surgical Outcomes}

Surgical outcomes including estimated blood loss
(EBL) and Simpson resection grade are shown in Table 3. The mean EBL was $660.4 \pm 637.1 \mathrm{ml}$ in the embolization group and $509.2 \pm 422.0 \mathrm{ml}$ in the nonembolization group $(p=0.17)$. Overall, the Simpson resection grade achieved did not differ between groups $(\mathrm{p}=0.15)$. Simpson grade IV was observed in 17 patients $(32.7 \%)$ in the embolization group and 13 patients $(25.0 \%)$ in the nonembolization group ( $\mathrm{p}=0.39$; OR 1.46 [95\% CI 0.62-3.42]). In 17 patients with a Simpson grade IV resection in the embolization group, the extent of the excision ranged from $85 \%$ to 99\%. In 13 patients with a Simpson grade IV resection in the nonembolization group, the extent of the excision ranged from $90 \%$ to $97 \%$.

\section{Procedural Complications}

Embolization- and surgery-related complications are shown in Table 4 . A total of 3 patients $(5.8 \%)$ experienced a complication related to the embolization procedure. Two (3.8\%) of these patients experienced increased intracranial pressure (ICP) related to cerebral edema from postembolization tumor infarction. Both of these patients were taken emergently to the operating room for decompression and

TABLE 4. Procedural complications

\begin{tabular}{|c|c|c|c|c|}
\hline Complication & $\begin{array}{l}\text { Embolization } \\
\text { Cohort }(n=52)\end{array}$ & $\begin{array}{l}\text { Nonembolization } \\
\text { Cohort }(n=52)\end{array}$ & $p$ Value & Odds Ratio $(95 \% \mathrm{Cl})$ \\
\hline \multicolumn{5}{|l|}{ Embolization } \\
\hline Increased ICP & 2 & NA & & \\
\hline Groin hematoma & 1 & NA & & \\
\hline Total & $3(5.8 \%)$ & NA & & \\
\hline \multicolumn{5}{|l|}{ Surgery } \\
\hline CSF leak/hydrocephalus & 5 & 3 & & \\
\hline Infection & 3 & 1 & & \\
\hline Postop cerebral edema & 1 & 1 & & \\
\hline Postop hemorrhage & 1 & 2 & & \\
\hline Postop resp failure & 1 & 0 & & \\
\hline Seizure & 0 & 2 & & \\
\hline Sinus occlusion & 0 & 1 & & \\
\hline Total & $11(21.2 \%)$ & $10(19.2 \%)$ & 0.81 & $1.12(0.43-2.94)$ \\
\hline Combined & $14(26.9 \%)$ & $10(19.2 \%)$ & 0.35 & $1.54(0.62-3.89)$ \\
\hline
\end{tabular}

$\mathrm{NA}=$ not applicable; resp = respiratory.

Values are presented as the number of patients or as the number (\%) of patients unless otherwise indicated. 
TABLE 5. Patient outcomes

\begin{tabular}{|c|c|c|c|c|}
\hline Outcome & $\begin{array}{c}\text { Embolization } \\
\text { Cohort }(n=52)^{*}\end{array}$ & $\begin{array}{c}\text { Nonembolization } \\
\text { Cohort }(n=52)\end{array}$ & $p$ Value & Odds Ratio $(95 \% \mathrm{Cl})$ \\
\hline \multicolumn{5}{|l|}{ Embolization } \\
\hline Hemiparesis (transient) & 1 & NA & & \\
\hline Facial palsy (chronic) & 1 & NA & & \\
\hline Total & $2(3.8 \%)$ & NA & & \\
\hline \multicolumn{5}{|l|}{ Surgery } \\
\hline Hemiparesis (transient) & 2 & 1 & & \\
\hline Hemiparesis (chronic) & 1 & 1 & & \\
\hline CN III palsy (chronic) & 0 & 1 & & \\
\hline Visual deficit (transient) & 1 & 0 & & \\
\hline Visual deficit (chronic) & 0 & 1 & & \\
\hline Swallow weakness (chronic) & 1 & 0 & & \\
\hline Decreased hearing (transient) & 0 & 1 & & \\
\hline Decreased hearing (chronic) & 0 & 1 & & \\
\hline Altered mental status (transient) & 1 & 1 & & \\
\hline Total & $6(11.5 \%)$ & $7(13.5 \%)$ & 0.77 & $0.84(0.26-2.69)$ \\
\hline Combined new neurological deficits & $8(15.4 \%)$ & $7(13.5 \%)$ & 0.78 & $1.17(0.39-3.50)$ \\
\hline mRS score at last follow-up & & & 0.14 & \\
\hline 0 & $29(58.0 \%)$ & $20(38.5 \%)$ & & \\
\hline 1 & $14(28.0 \%)$ & $24(46.2 \%)$ & & \\
\hline 2 & $5(10.0 \%)$ & $4(7.7 \%)$ & & \\
\hline 3 & $1(2.0 \%)$ & $1(1.9 \%)$ & & \\
\hline 4 & 0 & $3(5.8 \%)$ & & \\
\hline 5 & $1(2.0 \%)$ & 0 & & \\
\hline 6 & 0 & 0 & & \\
\hline \multicolumn{5}{|l|}{$\begin{array}{l}\text { mRS score at last follow-up (dichoto- } \\
\text { mized) }\end{array}$} \\
\hline $0-2$ & $48(96.0 \%)$ & $48(92.3 \%)$ & 0.43 & $0.50(0.09-2.86)$ \\
\hline $3-6$ & $2(4.0 \%)$ & $4(7.7 \%)$ & & \\
\hline mRS score improved at last follow-up & $25(50.0 \%)$ & $15(28.8 \%)$ & 0.03 & $2.5(1.1-5.6)$ \\
\hline
\end{tabular}

tumor resection. One patient (1.9\%) developed a large groin hematoma (EBL of $1 \mathrm{~L}$ ) that was not immediately seen by the medical staff because it was covered by surgical drapes. This patient was successfully managed with manual pressure and a blood transfusion.

As seen in Table 4, the surgical complication profile related to meningioma resection was very similar between the embolization and nonembolization groups. The most common complication in both groups was CSF leak $(9.6 \%[n=5]$ and $5.8 \%[n=3]$ in embolization and nonembolization groups, respectively). A total of 11 patients $(21.2 \%)$ experienced a surgical complication in the embolization group, compared to 10 patients $(19.2 \%)$ in the nonembolization group $(\mathrm{p}=0.81$; OR 1.12 [95\% CI $0.43-2.94])$.

The total number of combined endovascular and surgical complications was 14 (26.9\%) in the embolization and $10(19.2 \%)$ in the nonembolization group ( $\mathrm{p}=0.35$; OR 1.54 [95\% CI 0.62-3.89]).

\section{Patient Outcomes}

Clinical outcomes are shown in Table 5. A total of 8 patients (15.4\%) in the embolization group and 7 patients $(13.5 \%)$ in the nonembolization group experienced a new neurological deficit ( $\mathrm{p}=0.78$; OR 1.17 [95\% CI $0.39-3.50])$. In the embolization group, the new deficits in $2(3.8 \%)$ of these patients were the result of the endovascular procedure. One patient $(1.9 \%)$ with a tentorial meningioma experienced a small infarct in the medulla after embolization, which led to contralateral hemiparesis. The other patient (1.9\%) developed a House-Brackmann grade III facial palsy after embolization of a petroclival meningioma. In the embolization group, $3(5.8 \%)$ new neurological deficits were chronic and $5(9.6 \%)$ were transient, after both embolization and surgery. In the nonembolization group, 4 (7.7\%) new neurological deficits were chronic and $3(5.8 \%)$ were transient.

The mean follow-up durations for the embolization and 
nonembolization groups were $34.8 \pm 31.5$ months and 32.8 \pm 28.7 months, respectively $(\mathrm{p}=0.63)$. The $\mathrm{mRS}$ scores at last follow-up visit could not be determined for 2 patients in the embolization group. The final mRS scores did not significantly differ between groups $(p=0.14)$, including when final outcome was stratified by good versus poor functional status (mRS score of 0-2 in 96.0\% of embolization patients vs an mRS score of 0-2 in $92.3 \%$ of nonembolization patients; $\mathrm{p}=0.43$; OR 0.50 [95\% CI 0.09-2.86]). When comparing the final $\mathrm{mRS}$ score to the preoperative mRS score, patients in the embolization group were more likely than patients in the nonembolization group to have an improvement in the score $(50.0 \%$ vs $28.8 \% ; \mathrm{p}=0.03$; OR 2.5 [95\% CI 1.1-5.6]).

\section{Subgroup Analysis Excluding Convexity Meningiomas}

A subgroup analysis excluding patients with convexity meningiomas was performed to determine whether analysis of only deep/skull base tumors would yield a difference in outcomes. There were no statistically significant differences for the embolization group $(n=35)$ compared to the nonembolization group $(\mathrm{n}=35)$ in terms of EBL $(629.0$ $\pm 618.3 \mathrm{ml}$ vs $536.4 \pm 429.1 \mathrm{ml} ; \mathrm{p}=0.49)$, $\mathrm{mRS}$ score $>2$ (3.0\% vs $8.6 \% ; p=0.33$ ), or Simpson grade IV resection ( $42.4 \%$ vs $28.6 \%$; $\mathrm{p}=0.23$ ).

\section{Discussion}

We performed a retrospective matched cohort study of patients who underwent resection of WHO grade I intracranial meningiomas with and without preoperative embolization, controlling for patient age, tumor size, tumor laterality, tumor location, tumor invasion into a major dural sinus, and tumor encasement of the ICA or MCA. Our results showed no difference between the embolization and nonembolization cohorts for the following surgical outcomes: 1) surgical EBL, 2) Simpson resection grade, and 3) development of a new neurological deficit. Clinically, patients treated with preoperative embolization were more likely to have an improvement in functional status, but the likelihood of being functionally independent at last follow-up did not differ between groups.

To the best of our knowledge, our study is the first in the literature to control for specific tumor parameters before comparing the surgical outcomes of embolization and nonembolization cohorts treated for intracranial meningiomas. These parameters were chosen because of the significant degree to which they can affect the technical feasibility of meningioma resection, based on our own personal experience as well as reports in the literature. ${ }^{6,9,14}$ Brandel et al. ${ }^{4}$ recently used propensity score matching to compare 413 embolization patients to 413 nonembolization patients from the National (Nationwide) Inpatient Sample (NIS) database. They found that preoperative embolization was associated with postoperative cerebral edema $(p=0.009)$, postoperative anemia or transfusion $(p=0.003)$, and nonroutine discharge $(\mathrm{p}=0.039)$. While these data represent interesting findings that had not been previously reported, the use of a nationwide database prevented the investigators from controlling for any tumor-related parameters before comparing cohorts. Thus, it is unclear if the embo- lization patients in their study possessed a widely different set of meningiomas (i.e., size, location, complexity, vascular encasement, brain invasion) than the nonembolization patients. Additionally, the NIS database does not contain specific clinical or radiological outcomes, which limited the authors' ability to draw more detailed conclusions as to the effects of preoperative embolization on patient outcomes.

Meningiomas targeted for preoperative embolization tend to be larger and in deeper locations than those not referred for embolization. ${ }^{17}$ Brandel et al. ${ }^{4}$ concluded from their analysis of the NIS database that meningiomas referred for preoperative embolization represent a distinct clinical entity and that these patients often require additional clinical care. While the embolization cohort in this study represented a minor subset of meningioma patients treated at our institution during the study period, the high clinical volume at our center allowed us to create an independent matching cohort for comparison. We observed a significant difference before matching between those patients undergoing preoperative embolization and those not undergoing embolization in terms of tumor size $(\mathrm{p}<$ $0.001)$, tumor location $(p<0.001)$, and the presence of sinus invasion $(\mathrm{p}=0.05)$. This suggests that, likely due to inherent surgeon selection bias, meningiomas referred for preoperative embolization represent a unique subset of tumors at our institution.

The retrospective nature of this study prevented us from polling surgeons on the perceived ease of meningioma resection. This has been studied previously with mixed results, with some studies reporting that tumor softening is noticeable to surgeons after embolization and others reporting that it is not. ${ }^{2,12}$ There is no consensus on when it is best to operate on patients with meningiomas after embolization, but some data suggest that a longer waiting period (up to 7 days) between embolization and resection could allow for more tumor necrosis. 7,15 Others have argued that the intraoperative benefits of embolization (tumor necrosis and softness) can only be perceived when complete angiographic devascularization of the tumor has been achieved. ${ }^{2,3}$ Unfortunately, complete devascularization remains a technically challenging feat for large tumors with an extensive blood supply. Additionally, complete devascularization is defined by subjective interpretation of the angiographic blush, making this factor difficult to analyze objectively. Lastly, one must also consider that the risk of complications from embolization likely increases with more aggressive tumor devascularization.

New embolysates such as Onyx have the ability to deeply penetrate and occlude meningioma-supplying vascular pedicles in a more controlled fashion than previously used agents and, thus, may offer an improved morbidity profile when compared with those described historically. ${ }^{23}$ The morbidity rate associated with preoperative embolization has decreased significantly as endovascular technique and strategy have evolved. ${ }^{20}$ Feeding vessels arising from the ICA are embolized in a very selective manner because of the risk of embolysate reflux into the intracranial circulation. ${ }^{24}$ Similarly, particular caution is taken with embolization of external carotid artery branches that possess possible extracranial-intracra- 
nial anastomoses or distal cranial nerve supply. ${ }^{10,24}$ The most serious complication of preoperative embolization remains increased ICP from embolization-induced tumor necrosis and cerebral edema, which was seen in $2(3.8 \%)$ of 52 patients in this study. Some believe that embolization using small particles increases this risk as particles penetrate small terminal vessels with no collateral supply, but cases of increased ICP have been observed with all types of embolysates. ${ }^{1,5,16}$

In general, preoperative embolization is used selectively at our institution on a case-by-case basis, typically dictated by surgeon preference. It is commonly considered for lesions thought to be deep-seated hemangiopericytomas, which tend to have very large, deep feeding vessels amenable to embolization. In future studies, we hope to report our outcomes with preoperative embolization for these hypervascular lesions. This study demonstrates that preoperative embolization can be performed with an acceptable rate of morbidity and that significant tumor devascularization can be achieved. Although the proportion of patients with good final mRS scores was not different between groups, the mRS score was not used in propensity score matching, so we also analyzed the rate of mRS score improvement. Our finding that improvement in individual mRS scores was more common in the embolization group suggests that preoperative embolization has a continued role in the management of appropriately selected meningioma patients. In the context of our study, it is difficult to hypothesize why this was observed in the absence of differing surgical outcomes, but unmeasured surgical variables that could have favored the embolization group may have accounted for this discrepancy, such as ease of dissection. ${ }^{11,12,15}$ Future studies are needed to better elucidate which subset of meningioma patients benefits the most from preoperative embolization.

Reported outcomes after preoperative embolization have varied widely in the literature, limiting consensus of its utility in meningioma management. ${ }^{20}$ The goal of this study was to minimize confounding variables between the embolization and nonembolization cohorts by controlling for specific, detailed, tumor-related parameters. Still, our study is limited by the small subset of patients analyzed over the treatment period, which may have resulted in this study being underpowered to detect small but clinically significant differences between groups, as well as the possibility that unmeasured confounding variables existing between groups were not considered. For example, we did not control for vascularity on preoperative MRI scans because the predictability of tumor vascularity on MRI has been inconsistent. We were also unable to calculate preoperative tumor volumes for all patients due to limitations in outpatient imaging software for patients with preoperative MRI studies performed prior to 2009, preventing us from using preoperative volume as a matching variable. Thus, because tumor diameter was not matched to the desirable degree, we could not calculate preoperative tumor volumes for all patients, and preoperative tumor vascularity was not analyzed; it is possible that the embolization cohort contained a more challenging subset of meningiomas than the nonembolization cohort, despite our best efforts to match the groups.
Our relatively rare use of preoperative embolization over the treatment period may suggest that we have an institutional bias against its use, which could further influence the results of this study. Because several surgeons contributed patients to the study cohort and there was no defined protocol for the amount of time between embolization and surgery, individual surgeon's techniques and patient selection may also have biased our results. We grouped skull base tumors into only 3 categories (anterior, middle, and posterior), which could have oversimplified intracranial location as a preoperative variable, and blood loss estimated by the anesthesiologist and operating surgeon has been shown to be potentially inaccurate. ${ }^{22}$ Additionally, the inclusion of only WHO grade I meningiomas in this study may limit the generalizability of our results to a neurosurgeon's preoperative treatment planning, since the tumor grade is not known before surgery. Finally, we were unable to analyze important socioeconomic outcomes, such as hospital cost and length of hospital stay. These are important variables when weighing the pros and cons of a neoadjuvant therapy and should be included in future studies.

\section{Conclusions}

After controlling for patient age, tumor size, tumor laterality, tumor location, tumor invasion into a major dural sinus, and tumor encasement of the ICA or MCA, preoperative tumor embolization intended to decrease tumor vascularity did not improve the surgical outcomes of patients with WHO grade I intracranial meningiomas, but it did lead to a greater chance of clinical improvement compared to patients not treated with embolization.

\section{Acknowledgments}

We thank the staff of Neuroscience Publications at Barrow Neurological Institute for assistance with manuscript preparation.

\section{References}

1. Bendszus M, Monoranu CM, Schütz A, et al. Neurologic complications after particle embolization of intracranial meningiomas. AJNR Am J Neuroradiol. 2005;26(6):1413-1419.

2. Bendszus M, Rao G, Burger R, et al. Is there a benefit of preoperative meningioma embolization? Neurosurgery. 2000;47(6):1306-1312.

3. Borg A, Ekanayake J, Mair R, et al. Preoperative particle and glue embolization of meningiomas: indications, results, and lessons learned from 117 consecutive patients. Neurosurgery. 2013;73(2)(Suppl Operative):ons244-ons252.

4. Brandel MG, Rennert RC, Wali AR, et al. Impact of preoperative endovascular embolization on immediate meningioma resection outcomes. Neurosurg Focus. 2018;44(4):E6.

5. Carli DF, Sluzewski M, Beute GN, van Rooij WJ. Complications of particle embolization of meningiomas: frequency, risk factors, and outcome. AJNR Am J Neuroradiol. 2010;31(1):152-154.

6. Champagne PO, Lemoine E, Bojanowski MW. Surgical management of giant sphenoid wing meningiomas encasing major cerebral arteries. Neurosurg Focus. 2018;44(4):E12.

7. Chun JY, McDermott MW, Lamborn KR, et al. Delayed surgical resection reduces intraoperative blood loss for embolized meningiomas. Neurosurgery. 2002;50(6):1231-1237.

8. Dean BL, Flom RA, Wallace RC, et al. Efficacy of endovas- 
cular treatment of meningiomas: evaluation with matched samples. AJNR Am J Neuroradiol. 1994;15(9):1675-1680.

9. Debernardi A, Quilici L, La Camera A, et al. Torcular meningioma with multi-venous sinus invasion: compensatory drainage veins and surgical strategy. World Neurosurg. 2018;109:451-454.

10. Geibprasert S, Pongpech S, Armstrong D, Krings T. Dangerous extracranial-intracranial anastomoses and supply to the cranial nerves: vessels the neurointerventionalist needs to know. AJNR Am J Neuroradiol. 2009;30(8):1459-1468.

11. Iacobucci M, Danieli L, Visconti E, et al. Preoperative embolization of meningiomas with polyvinyl alcohol particles: the benefits are not outweighed by risks. Diagn Interv Imaging. 2017;98(4):307-314.

12. Kai Y, Hamada J, Morioka M, et al. Appropriate interval between embolization and surgery in patients with meningioma. AJNR Am J Neuroradiol. 2002;23(1):139-142.

13. Law-ye B, Clarençon F, Sourour NA, et al. Risks of presurgical embolization of feeding arteries in 137 intracranial meningeal tumors. Acta Neurochir (Wien). 2013;155(4):707-714.

14. Meling TR, Da Broi M, Scheie D, Helseth E. Meningiomas: skull base versus non-skull base. Neurosurg Rev. 2019;42(1):163-173.

15. Nania A, Granata F, Vinci S, et al. Necrosis score, surgical time, and transfused blood volume in patients treated with preoperative embolization of intracranial meningiomas. Analysis of a single-centre experience and a review of literature. Clin Neuroradiol. 2014;24(1):29-36.

16. Przybylowski CJ, Baranoski JF, See AP, et al. Preoperative embolization of skull base meningiomas: outcomes in the Onyx era. World Neurosurg. 2018;116:e371-e379.

17. Raper DM, Starke RM, Henderson F Jr, et al. Preoperative embolization of intracranial meningiomas: efficacy, technical considerations, and complications. AJNR Am J Neuroradiol. 2014;35(9):1798-1804.

18. Rosen CL, Ammerman JM, Sekhar LN, Bank WO. Outcome analysis of preoperative embolization in cranial base surgery. Acta Neurochir(Wien). 2002;144(11):1157-1164.

19. Shah AH, Patel N, Raper DM, et al. The role of preoperative embolization for intracranial meningiomas. J Neurosurg. 2013;119(2):364-372.

20. Singla A, Deshaies EM, Melnyk V, et al. Controversies in the role of preoperative embolization in meningioma management. Neurosurg Focus. 2013;35(6):E17.
21. Smith JS, Cha S, Mayo MC, et al. Serial diffusion-weighted magnetic resonance imaging in cases of glioma: distinguishing tumor recurrence from postresection injury. J Neurosurg. 2005;103(3):428-438.

22. Ulusoy A, Demiroz S, Erdem S. How accurate is visual estimation of perioperative blood loss in adolescent idiopathic scoliosis surgery? Acta Orthop Traumatol Turc. 2018;52(4):267-271.

23. Vaidya S, Tozer KR, Chen J. An overview of embolic agents. Semin Intervent Radiol. 2008;25(3):204-215.

24. Waldron JS, Sughrue ME, Hetts SW, et al. Embolization of skull base meningiomas and feeding vessels arising from the internal carotid circulation. Neurosurgery. 2011;68(1):162169.

25. Yoon N, Shah A, Couldwell WT, et al. Preoperative embolization of skull base meningiomas: current indications, techniques, and pearls for complication avoidance. Neurosurg Focus. 2018;44(4):E5.

\section{Disclosures}

Dr. Ducruet is a consultant for Medtronic. Dr. Little reports ownership in Kogent and stock options in SPIWay.

\section{Author Contributions}

Conception and design: Nakaji, Przybylowski, Almefty, Little. Acquisition of data: Zhao, Baranoski, Borba Moreira, Gandhi. Analysis and interpretation of data: Nakaji, Przybylowski, Almefty. Drafting the article: Przybylowski, Baranoski, Almefty. Critically revising the article: Nakaji, Przybylowski, Zhao, Baranoski, Borba Moreira, Gandhi, Chapple, Almefty, Sanai, Ducruet, Albuquerque. Reviewed submitted version of manuscript: Nakaji, Almefty, Little. Statistical analysis: Chapple. Study supervision: Nakaji.

\section{Correspondence}

Peter Nakaji: c/o Neuroscience Publications, Barrow Neurological Institute, St. Joseph's Hospital and Medical Center, Phoenix, AZ. neuropub@barrowneuro.org. 